\title{
Using zebrafish to study the function of nephronophthisis and related ciliopathy genes [version 1; peer review: 1
}

\section{approved, 2 approved with reservations]}

\author{
Elisa Molinari (D1, Simon A. Ramsbottom¹, Veronica Sammut ${ }^{1}$, \\ Frances E. P. Hughes ${ }^{1}$, John A. Sayer (D)1,2 \\ ${ }^{1}$ Institute of Genetic Medicine, Newcastle University, Newcastle upon Tyne, NE1 3BZ, UK \\ ${ }^{2}$ Renal Services, Newcastle upon Tyne Hospitals NHS Foundation Trust, Newcastle upon Tyne, NE7 7DN, UK
}

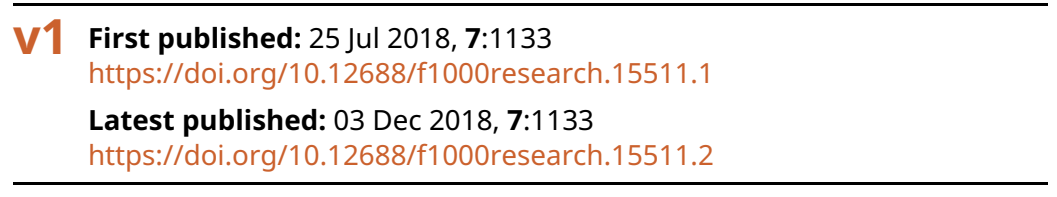

\section{Abstract}

Zebrafish are a valuable vertebrate model in which to study development and characterize genes involved in cystic kidney disease. Zebrafish embryos and larvae are transparent, allowing non-invasive imaging during their rapid development, which takes place over the first 72 hours post fertilisation. Gene-specific knockdown of nephronophthisis-associated genes leads to ciliary phenotypes which can be assessed in various developmental structures. Here we describe in detail the methods used for imaging cilia within Kupffer's vesicle to assess nephronophthisis and related ciliopathy phenotypes.

\section{Keywords}

Kupffer's vesicle; acetylated alpha-tubulin, primary cilia, somite

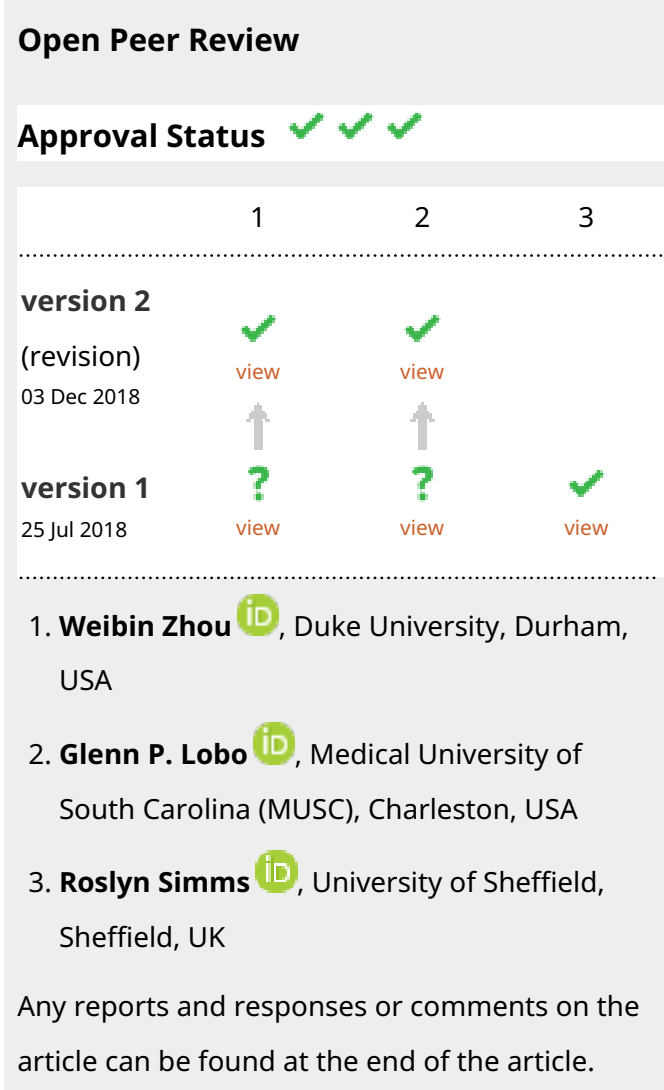


Corresponding author: John A. Sayer (john.sayer@ncl.ac.uk)

Author roles: Molinari E: Investigation, Methodology, Supervision, Writing - Original Draft Preparation, Writing - Review \& Editing; Ramsbottom SA: Investigation, Methodology, Supervision, Writing - Original Draft Preparation; Sammut V: Data Curation, Methodology, Writing - Original Draft Preparation; Hughes FEP: Formal Analysis, Methodology; Sayer JA: Funding Acquisition, Methodology, Resources, Supervision, Writing - Original Draft Preparation, Writing - Review \& Editing

Competing interests: No competing interests were disclosed.

Grant information: This work was supported by Northern Counties Kidney Research Fund, Kidney Research UK (PDF_003_20151124) and the Medical Research Council (MR/M012212/1).

The funders had no role in study design, data collection and analysis, decision to publish, or preparation of the manuscript.

Copyright: ( 2018 Molinari E et al. This is an open access article distributed under the terms of the Creative Commons Attribution License, which permits unrestricted use, distribution, and reproduction in any medium, provided the original work is properly cited. Data associated with the article are available under the terms of the Creative Commons Zero "No rights reserved" data waiver (CC0 1.0 Public domain dedication).

How to cite this article: Molinari E, Ramsbottom SA, Sammut $V$ et al. Using zebrafish to study the function of nephronophthisis and related ciliopathy genes [version 1; peer review: 1 approved, 2 approved with reservations] F1000Research 2018, 7:1133 https://doi.org/10.12688/f1000research.15511.1

First published: $25 \mathrm{Jul}$ 2018, 7:1133 https://doi.org/10.12688/f1000research.15511.1 


\section{Introduction}

The zebrafish, Danio rerio, is a powerful model in which to study inherited diseases ${ }^{1,2}$. A total of $70 \%$ of human genes have a zebrafish orthologue, which can be exploited in this model to determine expression and function ${ }^{3}$. Zebrafish can be used in a huge variety of manipulations, including forward genetic screens, targeted gene editing and pharmacological screening of new compounds. Here we describe techniques to visualize cilia within the developing node called Kupffer's vesicle $(\mathrm{KV})^{4}$ using fluorescence microscopy. These techniques can be successfully utilized to study nephronophthisis and related ciliopathy (NPHP-RC) genes ${ }^{5-7}$.

Nephronophthisis (NPHP) is an autosomal recessive inherited cystic kidney disease and a common cause of childhood and adolescent end-stage renal disease ${ }^{8}$. Genetically the disease is heterogeneous, with more than 20 genes involved in pathogenesis ${ }^{9,10}$. Notably, extra-renal manifestations are seen in $15 \%$ of patients, including disorders of the brain, retina, heart, liver and skeletal system. Remarkably, all genes known to cause NPHP and its associated syndromes express their protein products in the primary cilium, basal body or centrosome, leading to the umbrella term NPHP-RC for this group of conditions ${ }^{11}$. The disease pathogenesis of NPHP-RC is intimately related to primary ciliary structure and function (in terms of both sensing and signalling). Studying these diseases and how they affect the cilia (especially during development) has led to important mechanistic insights ${ }^{12}$.

$\mathrm{KV}$ in the zebrafish is a ciliated organ that functions in an analogous manner to the murine embryonic node ${ }^{13,14}$ and is important for the establishment of left-right (LR) asymmetry. The KV forms at around 10-12 hours post-fertilization (hpf) from a cluster of dorsal forerunner cells that have migrated to the tail bud. KV cells are ciliated and cilia mediated flow establishes LR body patterning and organ asymmetry. Typically there are around 50-60 cilia within the $\mathrm{KV}$, of length $3-5 \mu \mathrm{m}^{4,15}$. KV cilia are a mixture of motile and immotile. Changes in cilia number, motility and length can have a significant impact on the generation of flow and hence laterality $(\mathrm{KV} \text { function })^{16-18}$. Despite being a well-defined structure, locating and imaging $\mathrm{KV}$ is challenging and we hope to demystify this in the detailed methodological review presented here.

We aim to provide a precise methodological approach for the identification and staining of $\mathrm{KV}$ in developing zebrafish embryos. We hope to provide details of how to exploit this ciliated structure as a readout and disease model for inherited ciliopathy syndromes.

\section{Methods}

Materials

1. Phosphate buffered saline (PBS; 10x): $25.6 \mathrm{~g}$ $\mathrm{Na}_{2} \mathrm{HPO}_{4} \cdot 7 \mathrm{H}_{2} \mathrm{O}, 80 \mathrm{~g} \mathrm{NaCl}, 2 \mathrm{~g} \mathrm{KCl}, 2 \mathrm{~g} \mathrm{KH}_{2} \mathrm{PO}_{4}$. Make up to 1 litre with $\mathrm{H}_{2} \mathrm{O}$ and autoclave at $121^{\circ} \mathrm{C}$.

2. 4\% Paraformaldehyde (PFA) (Sigma-Aldrich ; catalogue number 16005) in PBS (note 1).

3. Methanol (VWR; catalogue number 20846.326).

4. Acetone (Sigma-Aldrich; catalogue number 24201).

5. Blocking solution: 5\% Bovine serum albumin (BSA) (Sigma-Aldrich; catalogue number A7906) in PBS containing $0.01 \%$ Tween-20 (Sigma-Aldrich; catalogue number P9416) and 0.1\% DMSO (Sigma-Aldrich ; catalogue number D8779).

6. Glass vials and lids (Qmx laboratories; catalogue number V0040, V0309).

7. Microscope slides (VWR; catalogue number 631-1550).

8. PVC insulation tape (Onecall; catalogue number CBBR7213) (note 7).

9. Primary antibodies for ciliary and KV staining e.g. antiacetylated $\alpha$-tubulin (Sigma-Aldrich; catalogue number T6793); anti-aPKC (1:500, SCBT) Santa Cruz Biotechnology; sc-216).

10. Secondary antibodies e.g. Alexa Fluor ${ }^{\circledR} 488$ Donkey Anti-Mouse IgG Antibody (Thermo Fisher Scientific; catalogue number A-21202); Alexa Fluor® 568 Donkey Anti-Rabbit IgG Antibody (Thermo Fisher Scientific; catalogue number A10042).

11. Mounting medium (Vectashield H-1200, Vector Laboratories).

\section{Fixing for KV imaging}

Imaging KV allows for easy analysis of cilia structure and function. It can be initially seen from the 5 somite stage (ss), but is most easily visualized between the 8 and 12 ss as it increases in size over this developmental window (Figure 2 and note 2).

To assess the age of the fish embryos, roll the embryo on to its side and count along the number of fully-formed somites, starting from the head to the tail (Figure 1). At the 10 ss the tail will begin to bud off from the yolk and this can be used as a secondary measure (Figure 2).

1. Fix $8-12$ ss Zebrafish embryos in $4 \%$ paraformaldehyde in phosphate buffered saline (4\% PFA in PBS) overnight at $4^{\circ} \mathrm{C}$. Do not remove the chorions before fixation (note 3 ).

2. Dehydrate the embryos in Methanol in a graded fashion from $25 \%$ to $100 \%$ methanol (in distilled water) in steps of $25 \%$, changing the wash every 10 minutes.

3. Store the embryos in $100 \%$ Methanol at $-20^{\circ} \mathrm{C}$ until required.

Antibody staining for cilia in KV

Throughout this procedure you should use glass vials and pipettes (note 4).

1. Rehydrate embryos slowly through a graded series of Methanol from $100 \%$ to $0 \%$ (in distilled water), changing the wash every 5 minutes. Keep embryos on ice throughout (note 5).

2. Wash twice more with distilled water to remove all traces of methanol

3. Incubate in chilled acetone at $-20^{\circ} \mathrm{C}$ for 5 minutes, to permeabilise the tissue 

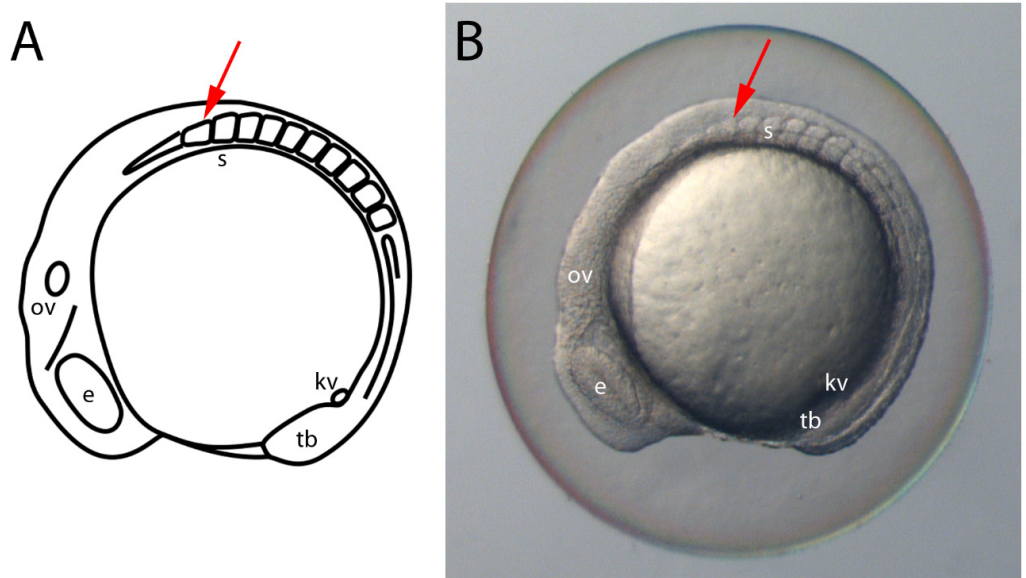

Figure 1. Staging embryos by somite counting. A schematic $(\mathbf{A})$ and light-microscopy image $(\mathbf{B})$ showing a lateral view of a 10 somite stage zebrafish embryo. The most anterior somite (red arrow) is slightly shorter and broader than more posterior somites. The generation of somites is tightly linked to the overall development of the embryo and therefore allows for accurate aging. e, eye; kv, Kupffer's vesicle; ov, otic vesicle; s, somites; tb, tail bud.
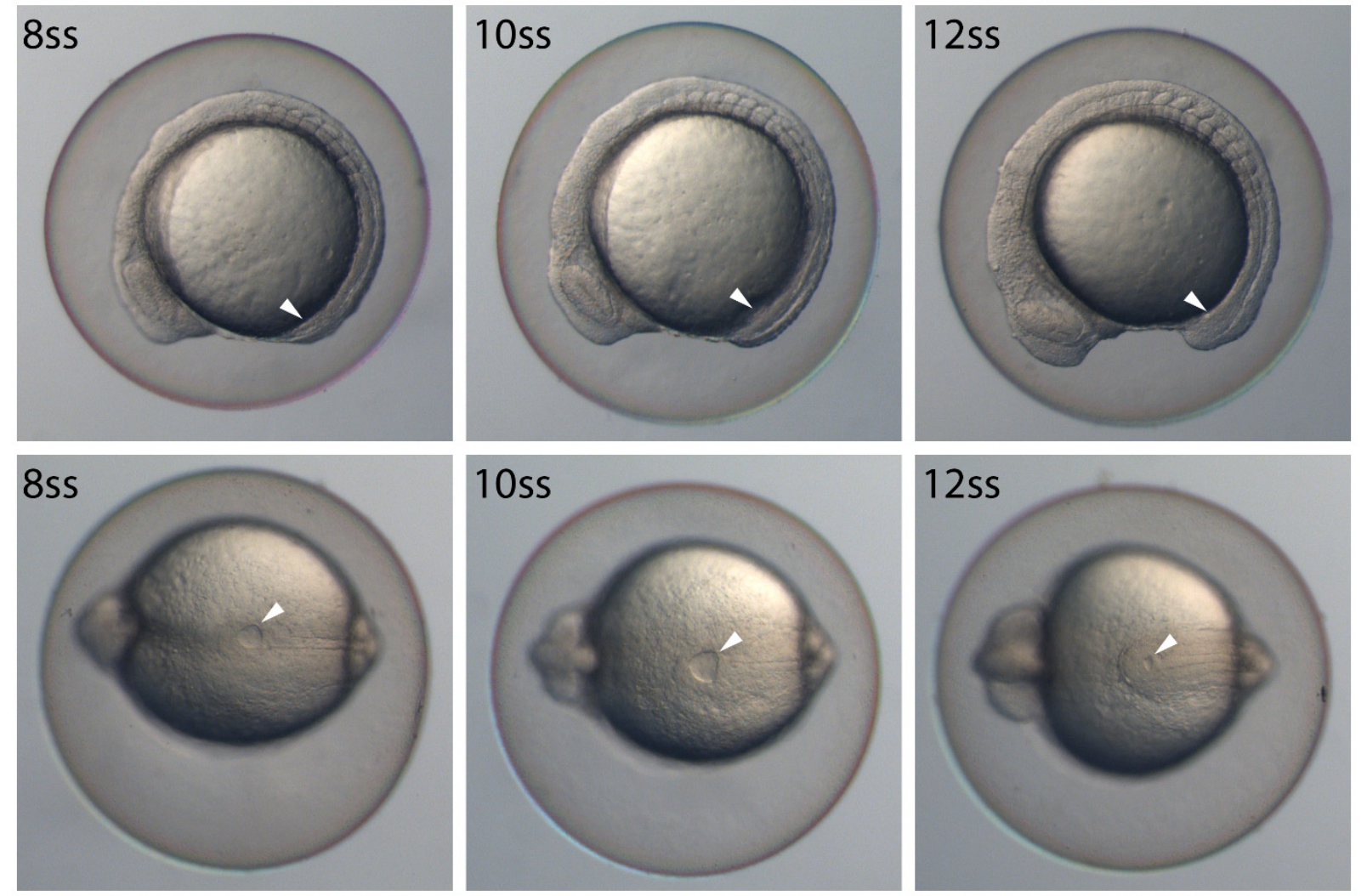

Figure 2. Kupffer's vesicle changes significantly in a short developmental window. Lateral (top panels) and ventral (bottom panels) views of zebrafish from the 8 somite stage (ss) to the $12 \mathrm{ss}$. Over this developmental window, Kupffer's vesicle (white arrowhead) expands and then shrinks, reaching its greatest size at the $10 \mathrm{ss}$. At $28.5^{\circ} \mathrm{C}$, zebrafish will form approximately two somites per hour, so the above panels represent a 4-hour period. 
4. Replace acetone with distilled water

5. Wash twice more with distilled water to remove all traces of acetone

6. Replace water with PBS (to reduce osmotic stress in de-chorionated tissues)

7. Manually de-chorionate the embryos using watchmaker's forceps or Green 21 gauge needles

8. Transfer embryos into $2 \mathrm{ml}$ glass vials

9. Incubate embryos in blocking solution for 2 hours

10. Incubate embryos in primary antibody in blocking solution overnight at $4{ }^{\circ} \mathrm{C}$ (note 6)

11. Wash embryos 3 times in PBS for 15 minutes or longer per wash

12. Incubate embryos in secondary antibody in blocking solution overnight at $4^{\circ} \mathrm{C}$

13. Wash embryos 3 times in PBS for 15 minutes or longer per wash

At the end of the staining procedure, embryos can be stored for up to two weeks at $4{ }^{\circ} \mathrm{C}$ in PBS, or long-term at $4^{\circ} \mathrm{C}$ in $2 \%$ PFA in PBS. Staining of embryos does not appear to be significantly diminished by longer-term storage.

\section{Imaging KV}

Once zebrafish embryos have been stained, the easiest way to visualize KV is by mounting the tail only in relief slides. Many tails can be imaged on a single slide, making slide preparation, imaging and storage easier.
Prepare slides

1. Take a glass slide and lay one layer of PVC tape on to it (note 7).

2. Cut a rectangular hole in the middle of the tape and remove this portion to create a well.

Prepare and mount embryos

1. Remove the tail tip of the embryos using forceps (note 8 and Figure 3)

2. Place up to 10 tail tips into the prepared well

3. Orient the tail tips so that they face upwards

4. Carefully remove the surrounding PBS (note 9)

5. Fill the well with mounting medium (note 10)

6. Place a cover slip over the well and seal the edges with nail varnish

Imaging can be undertaken with any fluorescent microscope that is able to remove out-of-focus light. While the KV can be seen with a traditional global excitation and capture system, there is too much noise resulting from the surrounding tissue. A confocal microscope offers the best image quality, but optical sectioning using structured illumination also gives good results.

\section{Validation}

Light microscopy images were acquired using a Leica MZ16F stereo microscope and Leica Application Suite V4.2. The presence of fluorescently labelled acetylated- $\alpha$ tubulin was confirmed in flat-mounted embryos using a Leica MZ16F stereo microscope with a Leica external light source for fluorescence excitation EL6000 with a red fluorescence protein filter.
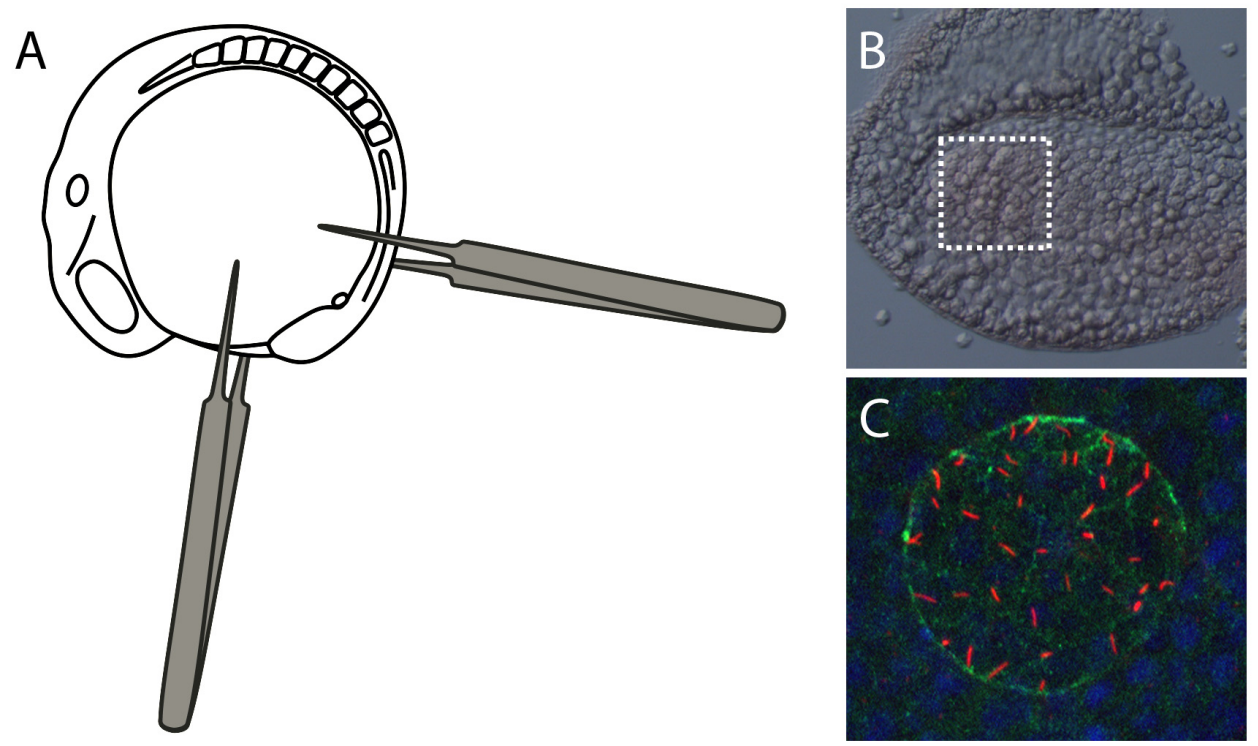

Figure 3. Mounting samples for visualization of Kupffer's vesicle. Schematic showing a 10 somite stage zebrafish embryo (A). Forceps can be used as depicted to separate the tail tip from the rest of the embryo. Excess yolk is then removed, and the tail tip mounted flat on to a microscope slide. (B) Bright field image overlaid with fluorescence image of flat-mounted tail tip. The white box depicts the location of Kupffer's vesicle. Fluorescence from acetylated- $\alpha$ tubulin (red) can be seen within this region. (C) Confocal image of Kupffer's vesicle, visualised using acetylated- $\alpha$ tubulin (red), aPKC (green) and DAPI (blue). 
Fluorescent microscopy images were captured using an Axio Imager Z1 fluorescent microscope (Zeiss), using a Colibri light source and filter sets for DAPI (blue), Alexa Fluor488 (green) and Alexa Fluor 594 (Red) with a 20X lens.

Zebrafish were maintained in a Home Office aquarium facility at a temperature of $28^{\circ} \mathrm{C}$. All zebrafish procedures were performed under Home Office UK license regulations.

\section{Notes}

\section{Preparation of paraformaldehyde}

Paraformaldehyde is dangerous in its powdered form and should be handled with care using a fume hood and mask. To successfully get PFA into solution it is necessary to warm it to $60^{\circ} \mathrm{C}$ and add sodium hydroxide to raise the $\mathrm{pH}$. At the correct temperature and $\mathrm{pH}$ ( $\mathrm{pH} 7$ ), the powder will go into solution rapidly. After cooling check the $\mathrm{pH}$ is correct. You can freeze aliquots (e.g. 10-20 ml) of PFA for later use. Once thawed, keep at $4^{\circ} \mathrm{C}$ for up to three days.

\section{Fixing zebrafish at the $10 \mathrm{ss}$}

At $28.5^{\circ} \mathrm{C}$, embryos reach the 10 ss approximately $14 \mathrm{hpf}$, making collection difficult (as this is typically very late at night, assuming fish lay eggs in the morning in a standard aquarium with unmodified night/day cycles). To facilitate collection of the $10 \mathrm{ss}$ embryos, it is possible to slow the development of the embryos down by placing them at a slightly lower temperature. At around $24^{\circ} \mathrm{C}$ the embryos will not reach the 10 ss until approximately $21 \mathrm{hpf}$ (i.e. the following morning).

\section{Embryo fixation}

It is usual to remove the chorion before fixation of fish embryos. At early stages, however, the embryos are very fragile and also the yolk tends to stick to almost anything when rehydrated. Thus it is best to leave the chorion on when undertaking the rehydration procedure, prior to immunostaining.

\section{Immunostaining in glass}

Embryos should be transferred using glass pipettes; they will stick to plastic and disintegrate easily. Immunostaining should be carried out in glass vials only. Using 2-ml glass vials allows for staining in a small volume of liquid $(<200 \mu \mathrm{l})$ which helps to reduce reagent costs and reduces the storage space required.

\section{Embryo rehydration}

Embryos are very fragile at this stage and should be handled with care. When rehydrating, only remove $50 \%$ of the solution they are in and replace with the next one (e.g. remove half of the $100 \%$ methanol, and replace with half of $75 \%$ methanol to give $87.5 \%$, then remove most of this and place into $75 \%$ methanol such that the steps are of roughly $12.5 \%$ ). Mixing methanol with water leads to an exothermic reaction so embryos should be kept on ice throughout to maintain their low temperature.

\section{Primary antibodies}

Any antibody which specifically detects ciliary proteins can be used for analysis of $\mathrm{KV}$, provided that it cross-reacts with zebrafish antigen. Staining of the intra-flagellar transport (IFT) machinery, the axoneme, or the ciliary membrane are all possible with this technique and allow for analysis of both structural and functional defects within zebrafish cilia. For simple detection of cilia structure the best antibody is anti-acetylated- $\alpha$ tubulin (Sigma-Aldrich; catalogue number T6793) at 1:500 for the ciliary axoneme. To visualise $\mathrm{KV}$ epithelium, counterstain with anti-aPKC at 1:500.

\section{Generation of imaging chamber}

While it is possible to purchase slides with wells of varying sizes, most commercially available slides have a circular bottom making it difficult to get a uniform distance from the cover slip to the sample. As a result only one or two samples can be placed in each. To generate a uniformly flat imaging surface, PVC tape can be used to convert any flat slide to a relief slide in which you can create an imaging chamber to fit your own size requirements. For KV visualization, one layer of tape provides ample depth to prevent the sample being crushed, while keeping the sample close to the cover slip. Detailed information and a visual demonstration of imaging chamber generation has been reported previously ${ }^{19}$.

\section{Embryo dissection for KV visualization}

To get a good image of KV it is best to remove the tail tip from the rest of the embryo and lay it flat. Using two pairs of forceps, pinch two-thirds of the way along the back of the embryo, to separate the posterior part of the embryo from the anterior, and between the head and tail to detach the tail from the yolk sac. Remove as much yolk from the remaining tissue as possible.

\section{Removal of PBS from the relief slide}

Due to the small size of the dissected zebrafish tail tip, it can be difficult to remove the PBS from the imaging chamber without disturbing the samples. To facilitate this process, use a razor blade to cut off a medium-sized $(20-200 \mu \mathrm{l})$ plastic micropipette tip at $45^{\circ}$. The cut tip can be placed flat on to the microscope slide allowing for aspiration of PBS without disturbing the samples.

\section{Mounting medium}

Mounting medium with an anti-fading agent is essential for the successful imaging of immunofluorescence-stained KV. Some mounting media is available in a hard-setting format e.g. Vectashield $\mathrm{H}-1500$, but it is preferable to use a non-setting medium such as Vectashield H-1200.

Dataset 1. Raw, uncropped images from which Figures 1-3 were generated

http://dx.doi.org/10.5256/f1000research.15511.d210727

Leftmost image, Figure 1; middle six images, Figure 2; rightmost two images, Figure 3 .

\section{Discussion}

The use of zebrafish for modelling genetic diseases has proven to be very significant. Zebrafish are advantageous given the presence of transparent developmental stages. They are straightforward to maintain and genetic manipulations can be performed with relative ease. Here we have focused on accessing and imaging the zebrafish $\mathrm{KV}$, a transient developmental structure with a lumen and ciliated epithelial cells lining it. The KV functions, via its cilia, serves as 
a 'left-right' organiser in order to determine left-right asymmetry within the zebrafish embryo ${ }^{13,14}$. Within the $\mathrm{KV}$, a single layer of epithelial cells surround a fluid-filled lumen into which they extend a motile cilium, generating asymmetric fluid flows that allow left-right patterning signals to be transmitted. Thus the KV is a simple yet accessible structure that is ideal for investigating cilia structure and function, and their role in inherited human ciliopathy syndromes. Nearly all new ciliopathy syndromes described in man use zebrafish, and their $\mathrm{KV}$ in particular, to gain insights into disease pathogenesis. Genetic knockdowns can cause defects in $\mathrm{KV}$ that may affect the size and structure of the organ as well as the cilia, and RNA rescue can determine the specificity of this affect. The study of KV therefore provides an accessible tool for the modelling of ciliopathies and interventions, such as genetic therapies and pharmacological agents, which may be used to rescue underlying cilia defects.
Data availability

Dataset 1. Raw, uncropped images from which Figures 1-3 were generated. Leftmost image, Figure 1; middle six images, Figure 2; rightmost two images, Figure 3. DOI: 10.5256/ f1000research.15511.d21072720.

\section{Competing interests}

No competing interests were disclosed.

\section{Grant information}

This work was supported by Northern Counties Kidney Research Fund, Kidney Research UK (PDF_003_20151124) and the Medical Research Council (MR/M012212/1).

The funders had no role in study design, data collection and analysis, decision to publish, or preparation of the manuscript.
1. Drummond IA: Kidney development and disease in the zebrafish. J Am SoC Nephrol. 2005; 16(2): 299-304. PubMed Abstract | Publisher Full Text

2. Song Z, Zhang X, Jia S, et al:: Zebrafish as a Model for Human Ciliopathies. $J$ Genet Genomics. 2016; 43(3): 107-20. PubMed Abstract | Publisher Full Text

3. Howe K, Clark MD, Torroja CF, et al:: The zebrafish reference genome sequence and its relationship to the human genome. Nature. 2013; 496(7446): 498-503. PubMed Abstract | Publisher Full Text | Free Full Text

4. Amack JD: Salient features of the ciliated organ of asymmetry. Bioarchitecture 2014; 4(1): 6-15.

PubMed Abstract | Publisher Full Text | Free Full Text

5. Simms RJ, Hynes AM, Eley L, et al:: Modelling a ciliopathy: Ahi1 knockdown in model systems reveals an essential role in brain, retinal, and renal development. Cell Mol Life Sci. 2012; 69(6): 993-1009. PubMed Abstract | Publisher Full Text

6. Chaki M, Airik R, Ghosh AK, et al.: Exome capture reveals ZNF423 and CEP164 mutations, linking renal ciliopathies to DNA damage response signaling. Cell. 2012; 150(3): 533-48.

PubMed Abstract | Publisher Full Text | Free Full Text

7. Slaats GG, Saldivar JC, Bacal J, et al.: DNA replication stress underlies renal phenotypes in CEP290-associated Joubert syndrome. J Clin Invest. 2015; 125(9): 3657-66.

PubMed Abstract | Publisher Full Text | Free Full Text

8. Simms RJ, Eley L, Sayer JA: Nephronophthisis. Eur J Hum Genet. 2009; 17(4) 406-16.

PubMed Abstract | Publisher Full Text | Free Full Text

9. Wolf MT, Hildebrandt F: Nephronophthisis. Pediatr Nephrol. 2011; 26(2): 181-94. PubMed Abstract | Publisher Full Text | Free Full Text

10. Srivastava S, Molinari E, Raman S, et al:: Many Genes-One Disease? Genetics of Nephronophthisis (NPHP) and NPHP-Associated Disorders. Front Pediatr. 2018; 5: 287.

PubMed Abstract | Publisher Full Text | Free Full Text

11. Hildebrandt F, Otto E: Cilia and centrosomes: a unifying pathogenic concept for cystic kidney disease? Nat Rev Genet. 2005; 6(12): 928-40. PubMed Abstract | Publisher Full Text

12. Slaats GG, Giles RH: Are renal ciliopathies (replication) stressed out? Trends Cell Biol. 2015; 25(6): 317-9.

PubMed Abstract | Publisher Full Text

13. Essner JJ, Vogan KJ, Wagner MK, et al.: Conserved function for embryonic nodal cilia. Nature. 2002; 418(6893): 37-8.

PubMed Abstract | Publisher Full Text

14. Kramer-Zucker AG, Olale F, Haycraft CJ, et al:: Cilia-driven fluid flow in the zebrafish pronephros, brain and Kupffer's vesicle is required for normal organogenesis. Development. 2005; 132(8): 1907-21. PubMed Abstract | Publisher Full Text

15. Wang G, Yost HJ, Amack JD: Analysis of gene function and visualization of cilia-generated fluid flow in Kupffer's vesicle. J Vis Exp. 2013; (73): e50038. PubMed Abstract | Publisher Full Text | Free Full Text

16. Montenegro-Johnson TD, Baker DI, Smith DJ, et al.: Three-dimensional flow in Kupffer's Vesicle. J Math Biol. 2016; 73(3): 705-25. PubMed Abstract | Publisher Full Text | Free Full Text

17. Smith DJ, Montenegro-Johnson TD, Lopes SS: Organized chaos in Kupffer's vesicle: how a heterogeneous structure achieves consistent left-right patterning. Bioarchitecture. 2014; 4(3): 119-25. PubMed Abstract | Publisher Full Text | Free Full Text

18. Lin $\mathrm{CY}$, Tsai MY, Liu YH, et al.: KIf8 regulates left-right asymmetric patterning through modulation of Kupffer's vesicle morphogenesis and spaw expression. J Biomed Sci. 2017; 24(1): 45.

PubMed Abstract | Publisher Full Text | Free Full Text

19. Fellgett SW, Ramsbottom SA, Maguire RJ, et al:: Using Confocal Analysis of Xenopus laevis to Investigate Modulators of Wnt and Shh Morphogen Gradients. J Vis Exp. 2015; (106): e53162. PubMed Abstract | Publisher Full Text | Free Full Text

20. Molinari E, Ramsbottom S, Veronica Sammut V, et al.: Dataset 1 in: Using zebrafish to study the function of nephronophthisis and related ciliopathy genes. F1000Research. 2018

Data Source 


\section{Open Peer Review}

\section{Current Peer Review Status:}

\section{Version 1}

Reviewer Report 05 September 2018

https://doi.org/10.5256/f1000research.16913.r37382

(c) 2018 Simms R. This is an open access peer review report distributed under the terms of the Creative Commons Attribution License, which permits unrestricted use, distribution, and reproduction in any medium, provided the original work is properly cited.

\section{Roslyn Simms}

University of Sheffield, Sheffield, UK

Molinari et al. present a well written and clear description of the methodology required to image the transient developmental zebrafish organelle, Kupffer's Vesicle (KV). Overall, they clearly show $\mathrm{KV}$ development using light microscopy and a confocal image of cilia in KV stained using acetylated-alpha tubulin.

Their method will definitely facilitate research to study the structure of KV and its cilia. They provide useful tips on how to overcome practical challenges. However it would be informative to include information on how to measure cilia length (for example software used) and how to calculate KV volume.

Similarly, additional methodological information will have to be added relating to studying the "function of KV", perhaps using live confocal imaging to study cilia motility, or this comment amended.

Minor points, which would help the reader:

- I suggest delete "easy" in the Methods section on "Fixing for KV imaging" as this relatively contradicts the challenge of imaging KV which you describe in the introduction.

- Consider including a magnified image of the white arrowed area of the lateral views in Figure 2.

Add information on how you identified the location of KV from the bright field image in Figure 3B.

In the notes section, add the number of $\mathrm{KV}$ you advise mounting on each slide for imaging.

Finally in the discussion, add some references to support your statements:"Nearly all new cilioopathy syndromes,,," and "genetic therapies and pharmacological agents" (the time window to do this will be relatively short).

Overall an informative methodological article for the zebrafish research community.

Is the rationale for developing the new method (or application) clearly explained? 
Yes

Is the description of the method technically sound?

Yes

Are sufficient details provided to allow replication of the method development and its use by others?

Yes

If any results are presented, are all the source data underlying the results available to ensure full reproducibility?

Yes

Are the conclusions about the method and its performance adequately supported by the findings presented in the article?

Partly

Competing Interests: No competing interests were disclosed.

I confirm that I have read this submission and believe that I have an appropriate level of expertise to confirm that it is of an acceptable scientific standard.

Reviewer Report 30 August 2018

https://doi.org/10.5256/f1000research.16913.r37381

(C) 2018 Lobo G. This is an open access peer review report distributed under the terms of the Creative Commons Attribution License, which permits unrestricted use, distribution, and reproduction in any medium, provided the original work is properly cited.

\section{Glenn P. Lobo}

School of Medicine, Department of Ophthalmology, Medical University of South Carolina (MUSC), Charleston, SC, USA

Molinari and colleagues present a detailed methodology to functionally access cilia structure in KV vessels of zebrafish.

I am especially impressed with the details provided, methodology setup and the clarity of the images in this manuscript.

Suggestions:

1. It would be beneficial to readers if authors provide an image of the "relief slides/ imaging chamber" used for mounting.

2. What type of microscope was used? Upright or inverted? An image of the actual zebrafish in the imaging chamber/ slides on the mounting stage of the microscope would also provide 
additional information about the set-up. What type of objective was used? Air or oil objective? Additional information on microscopy could be provided.

3. A more in-depth detail on optical sectioning using structured illumination (I presume using an Zeiss Apotome 2) would be beneficial.

4. Which program was used to calculate cilia length? Fiji or Image J? Please provide some additional details.

Is the rationale for developing the new method (or application) clearly explained?

Yes

Is the description of the method technically sound?

Yes

Are sufficient details provided to allow replication of the method development and its use by others?

Partly

If any results are presented, are all the source data underlying the results available to ensure full reproducibility?

Yes

Are the conclusions about the method and its performance adequately supported by the findings presented in the article?

Yes

Competing Interests: No competing interests were disclosed.

Reviewer Expertise: Ciliogenesis, vitamin A receptors, zebrafish, mouse models, microscopy, retinal degeneration, photoreceptors, kidney

I confirm that I have read this submission and believe that I have an appropriate level of expertise to confirm that it is of an acceptable scientific standard, however I have significant reservations, as outlined above.

Reviewer Report 13 August 2018

https://doi.org/10.5256/f1000research.16913.r36493

(C) 2018 Zhou W. This is an open access peer review report distributed under the terms of the Creative Commons Attribution License, which permits unrestricted use, distribution, and reproduction in any medium, provided the original work is properly cited.

Weibin Zhou 
Duke University, Durham, NC, USA

Molinari et al. presented a detailed description of the method they have developed to assess the function of ciliopathy-related genes using the zebrafish KV as a model system. In particular, they developed this method to image fluorescently labeled KV cilia such that (I assume) the morphology of those cilia can be analyzed. Overall the description is well written but a little more detail is needed to allow the readers to reproduce and use this method in their own studies. My major questions are as follows:

1. The KV cilia are either motile and immotile. I think the method in this manuscript is primarily addressing the morphology of cilia, but the authors did not present any method of analyzing the ciliary morphology after the illustrated imaging process. It would be critical for them to present their quantitative analysis of ciliary morphology based on the fluorescent images, to ensure the completeness of this manuscript.

2. It is not mentioned how many embryos were placed into each glass vial for immunostaining and the volume of staining solution for each sample. This is also pertinent to the quantitative analyses, as I wonder about the typical sample size needed for the quantitative analyses.

3. I think the intro and the discussion needs to be edited by a native English speaker to ensure there is no grammatical error.

Is the rationale for developing the new method (or application) clearly explained? Yes

Is the description of the method technically sound?

Yes

Are sufficient details provided to allow replication of the method development and its use by others?

Partly

If any results are presented, are all the source data underlying the results available to ensure full reproducibility?

Yes

Are the conclusions about the method and its performance adequately supported by the findings presented in the article?

Partly

Competing Interests: No competing interests were disclosed.

I confirm that I have read this submission and believe that I have an appropriate level of expertise to confirm that it is of an acceptable scientific standard, however I have significant reservations, as outlined above. 
The benefits of publishing with F1000Research:

- Your article is published within days, with no editorial bias

- You can publish traditional articles, null/negative results, case reports, data notes and more

- The peer review process is transparent and collaborative

- Your article is indexed in PubMed after passing peer review

- Dedicated customer support at every stage

For pre-submission enquiries, contact research@f1000.com 